https://doi.org/10.18485/kud_kiaz.2019.ch27

\author{
Нигяр Гусейнова \\ доцент кафедры «Регионоведения» \\ Азербайджанского Университета Языков
}

\title{
ЕДИНСТВО ТРАДИЦИОННОСТИ И СОВРЕМЕННОСТИ В АЗЕРБАЙДЖАНСКОЙ НАЦИОНАЛЬНОЙ КУЛЬТУРЕ
}

\begin{abstract}
SUMMARY
The article examines the status of the Azerbaijani national culture, its originality in the global cultural space. The author studied that morality and ethics are closely related to traditionalism, stabilizing in nature, brings to the attention that cultures dominated by traditionalistic lag behind development, and also emphasizes the need for modernism to be the basis of the ideology of modernism.
\end{abstract}

Key words: national culture, tolerance, multiculturalism, intercultural dialogue, coexistence, mutual enrichment, multicultural society.

Статус азербайджанской национальной культуры, ее самобытность в мировом культурном пространстве обуславливается тем, что она состоит из единства отражающей в себе многовековой опыт народа традиционности, с одной стороны, и современности, являющейся проявлением международных, всемирных достижений, с другой. Под традиционностью понимается «передающееся из поколения в поколение, охраняемое в обществе, социально-культурное наследие, которое в течение долгого времени жило благодаря человеческим объединениям и социальным группам». $\{4$, с.692\} 
Наряду с художественными, материальными, философскими, морально-эстетическими ценностями и достижениями, которые были созданы народом в азербайджанской национальной культуре, развиваются также ценности, которые были получены в процессе взаимодействия $\mathrm{c}$ другими нациями. Взаимоотношения традиционности и современности имеют актуальность во всех этапах развития нашей национальной культуры. Актуальность проблемы в том, что традиционность как важная духовная ценность, является формой культурной преемственности, феноменом сохранения культурного наследия, передачи из одного поколения в другое, слияния с современностью. Без наличия культурной преемственности невозможно познать современность в культуре, одним словом, традиционность и современность здесь объединяются. «Освоение новшеств, сохранение культурных символов, устойчивость, которых прошла испытанием временем, являются принципиально присущими традиционности чертами. Между устойчивостью и новшеством в каждой культуре имеется динамическое соотношение - баланс». $\{1$, с.77\}. Как видно, эти атрибуты составляют различные аспекты национальной культуры, показывают их самобытность и общность.

В традиционность входят материальное и духовное социокультурное наследие. Культурное наследие отражает исторически приобретенные народом достижения на этапе развития, опыт, который он хранит в своей памяти, систему ценностей, передаваемую новым поколениям. Культурные образцы, нормы, идеи, обряды являются духовным достоянием, относящимся к традиционности, феноменом, который связывает прошлое с настоящим и будущим. В этом смысле, он также участвует в современности, сливается с ним.

Азербайджанской национальной культуре, ее современности воздействуют процессы глобальной трансформации, выступая в качестве положительных факторов. В 
то же время, этот процесс, как общемировой процесс оказывает отрицательное влияние на национальную идентичность. Поэтому, рекомендуется снизить до минимума связанные с глобальными трансформациями риски, и максимально воспользоваться этими изменениями в культурной сфере. Современная «система ценностей должна охватывать мировой опыт и совместный опыт всех народов мира, их национально-культурные ценности». $\{2$, с.181\}. Значит, в нашей национальной культуре современность неразрывна с традиционностью. Сегодня сохранение и еще большее развитие традиционности - культурного наследия, которое мы имеем, стало крайне серьезной, необходимой проблемой.

В азербайджанской национальной культуре традиционность тесно связана с современностью. Точнее говоря, «культура прошлого вызывает интерес только тогда, когда она по прежнему современна или может еще и стать будущим». $\{5$, с. 485$\}$. Таким образом, насколько традиционна азербайджанская национальная культура, настолько она и современна.

Развиваясь в условиях многонациональности, многорелигиозности, и многоязычия в эпоху глобальных трансформаций, азербайджанская национальная культура демонстрирует взаимодействие разных культур, терпимость и гуманизм по отношению к культуре других народов.

Наша национальная культура подверженная в таких условиях модернизации, обновлению и инновационным процессам, сохраняя свою уникальность и специфичность отражает в себе также единство локальности и универсальности. Взаимоотношения традиционности и современности в национальной культуре нашей страны в качестве культурного феномена, состоящего из синтеза культур Востока и Запада, зависят от существования конкретно исторических социокультурных условий. В этой культуре традиционность обеспечивает преемственность, а современность новизну. Взаимная обусловленность тра- 
диционности и современности связано с тем, что если в этом единстве модернизация сязана с потенциальными источниками возникновения новых культурных традиций, то традиционность по большей части готовит почву для креативных процессов в национальной культуре. Благодаря гармоничному переплетению традиционности и современности в нашей национальной культуре, наша культура динамично развивается. Если этот баланс нарушится, и в одностороннем порядке будет дано предпочтение традиционности, то в таком случае, она может стать препятствием на пути культурного развития, тогда культура может утратить свою устойчивость, может нарушится принцип преемственности в развитии культуры, может снизиться его ценность.

Ядро азербайджанской национальной культуры составляет азербайджанство, олицетворяющее в себе единство традиционности с современностью, единство общих ценностей и богатств, национальность и культурное разнообразие. «Для многонационального, многорелигиозного, многоязычного Азербайджана эту идеологию выдвинула сама историческая реальность. Воистину, Азербайджан, где проживают представители самых различных национально-этнических групп является уникальным географическим, геополитическим и культурным пространством» $\{1$, с.251\}. Национальная азербайджанская культура является носителем тюркства, азербайджанства, исламизма и современности, локальности и универсальности. Все это является демонстрацией открытости миру, гуманизма, терпимости, человеколюбия. Эта культура отражает единство находящихся во взаимосвязи фольклора, литературы, языков и диалектов, разнообразия образа жизни и религиозных взглядов.

В условиях глобальных трансформаций, когда возникла угроза культурной однородности, в нашей стране царят культурное разнообразие и единство культурного плюрализма с идентичностью. Сегодня происходят из- 
менения в мировоззренческих, социокультурных, либеральных, идейно-политических, культурологических, межкультурных парадигмах культур, одновременно в условиях интеграции, дезинтеграции, дифференциации культур, возникают новые виды культурных ценностей. В таких условиях меняются мировоззренческие, аксиологические парадигмы азербайджанской культуры, происходит пересмотр ценностей. В подобном состоянии взаимоотношений традиционности и современности, на новые социокультурные ценности влияют факторы менталитета, самосознания. Азербайджанское государство играет решающую роль в осуществлении модернизации культуры, а также сохранении национальной идентичности. В качестве основных направлений взаимоотношений государства и культуры, можно указать на следующее: «сохранение национально-культурного наследия, развитие региональной культуры, актуализация межкультурного диалога между различными этническими объединениями внутри страны и на международной арене, поддержка народного творчества, противостояние негативному влиянию коммерциализации в культурной сфере, поддерживание новаторства и обновления в культуре». $\{6$, с.14\}. В этом смысле, Азербайджанская Республика, идущая по пути демократического общества, строительства правового государства осуществляет культурную политику, которая служит единству традионности и современности в культуре, обеспечивает верховенство закона в этой области. Это проявляет себя во всех этапах культурных ценностей - и в создании, и в сохранении, распространении и освоении новых ценностей.

Принятый в Азербайджане Закон «О культуре» служит упрочению единства традиционности и современности в национальной культуре. Закон заложил правовую базу для антимонопольной государственной политики в области культуры, а также обеспечения уникальности, национальной неповторимости культур. Законом гаранти- 
руется сохранение и развитие культурного наследия как титульной нации, так и всех этнических групп, исторически проживающих на территории Азербайджанской Республики, а также возможность создания общественных объединений и организаций, занимающихся культурной деятельностью. Вмешательство государства в эту сферу ограничивается лишь запретом насилия, расовой, национальной и религиозной нетерпимости, порнографии и наркомании. Предусмотрено обеспечение фактического применения таких запретов в порядке судебной процедуры. Согласно закону, иная форма вмешательства в культурную деятельность не допускается. В целом, в рамках этого закона, были решены ряд вопросов, связанных с функционированием и развитием культуры. $\{2$, с.191-192\}.

Таким образом, интегрирующаяся в мировое культурное пространство, Азербайджанская Республика, является постсоветской страной, которая проводит идейно-культурную политику, дающую толчок к развитию традиционности и современности, сохранению культурного разнообразия и национальной самобытности, страной которая верна своим историческим и культурным традициям, и пользуется процессом интеграции и глобальной трансформации во имя развития и модернизации своей культуры, в то же время, оберегает свое культурно-историческое наследие и менталитет от разрушительного воздействия глобальной культурной стандартизации, и идет по пути строительства демократического общества и правового государства.

Возникновение глобальной универсальной культуры актуализирует взаимоотношения традиционности и современности. Традиционность и современность в национальной культуре, наряду с устойчивостью, выявляют также наличие противоречивых моментов.

Традиция, наряду со стабильностью и долговечностью, создает также инерцию в культуре. Поэтому без развития, обновления, модернизации, модернизации, культу- 
ра может застыть в статичном состоянии. В этом смысле, универсальность культур требует единства традиционности и современности. Видный философ М.С.Каган говоря о взаимоотношениях традиционности и современности в философских и культурных дискурсах "подчеркивает многомерность источников, определяющих отношения традиций и новаций в философии и культуре. Автор выделяет следующие источники: некие процессы, протекающие внутри самой культуры: дух времени, который на одних этапах истории культуры канонизирует традиционность, а на других - современность и новаторство $\{8$, с.40-41\}. Как видно, во всех этапах развития культур традиционность существовала в состоянии взаимодействия с современностью.

Глобальные трансформации и интеграционные процессы, с одной стороны, сближают народы мира, обогащают их культуру и, с другой, усиливают единство национализма и универсализма, традиционности и современности. С этой точки зрения, статья азербайджанского исследователя академика Р.Мехтиева под названием «О глобальной интеграции и пересмотре философской мысли в Азербайджане» особенно привлекает внимание. Автор указывает, что интеграционные тенденции в условиях глобализации объединяют все нации и государства, в то время как повышение интенсивности глобальных трансформаций требует пересмотра традиционных ценностей. Для этого он советует пересмотреть место, идейный потенциал и возможности современного философского наследия (а также всего культурного наследия - Н.Г.) в системе современной мировой философской мысли... Существует большая необходимость развития региональных отношений в деле сближения традиций философской мысли Востока и Запада и ...создания общей концептуальной системы в процессе глобализации... Сегодня, помимо определения того, какое наследие древнее, и актуальнее, и продолжения классических фило- 
софских традиций, важно придавать особое значение тем теориям, которые оперативно анализируют динамически меняющуюся реальность». $\{3$, с. 3$\}$. В связи с этим, автор считает проявление интеллектуальной инициативы XXI века Азербайджаном в качестве места диалога традиций и новшеств, необходимыми требованиями дня.

Другой азербайджанский исследователь, доктор философских наук, профессор И.Мамедзаде, подойдя к проблеме с несколько иного ракурса показывает, что «Необходимо понимать важность различий между нравами традиционных и модернизирующихся обществ в условиях глобализации и нового мирового порядка». $\{4, \mathrm{c.} 42\}$. Автор справедливо указывает на то, что мораль и нравственность тесно связаны с традиционностью, носят стабилизирующий характер, доводит до внимания, что культуры, в которых доминирует традиционность отстают от развития, а также подчеркивает необходимость того, что основу идеологии модернизма составляет традиционность.

Таким образом, традиционность и современность в национальной азербайджанской культуре не носят статического характера, а культурная динамика пронизывает все его сферы. Это развитие, обновление, осовременивание, модернизация функционируют в условиях тесного взаимодействия с традиционностью. Глобальные преобразования, помимо сохранения национальной самобытности, традиционных культурных ценностей в культуре Азербайджана, открывают дорогу также к взаимодействию с другими культурами, обогащению и модернизации. Тем самым, национальная культура Азербайджана занимает свое почетное, достойное место во всемирном культурном пространстве. 


\section{Список использованной литературы}

Асланова Р. Глобализация и культурное разнообразие. Баку: «ЭЛМ», 2004, 264 с. (на азерб.)

Мамедалиева С. Философские аспекты культуры в условиях глобализации. Баку: «Нурлар». 2006, 224 с. (на азерб.)

Мехтиев Р. О глобальной интеграция и пересмотре философской мысли в Азербайджане // Газета «Азербайджан», 2009, с.3. (на азерб.)

Мамедзаде И. Об актуальности философии в условиях глобализации и модернизации. Баку: «Текнур», 2009, 226 с. (на азерб.)

Сэмер Э. Избранные труды по языкознанию и культурологии. Москва: «Наука», 1993, 568 с.

Шелупенко Н.Е. Современная духовная культура Беларуси: взаимодействие традиций и новаций: автореф. дисс. ...канд. культурологии. Минск, 2005, 27 с.

Философский энциклопедический словарь. Москва: «Наука», $796 \mathrm{c}$

Каган М.С. Традиции и новации в современных философских дискурсах //Материалы круглого стола 8 июня 2001 г. Санкт-Петербург. Серия: “Simposium” Вып.: 14. СПб.: Санкт Петербургское философское общество, 2001, с.39-42.

\section{PЕЗЮМЕ}

В статье исследуется статус азербайджанской национальной культуры, ее самобытность в мировом культурном пространстве. Автор изучил что, мораль и нравственность тесно связаны с традиционностью, носят стабилизирующий характер, доводит до внимания, что культуры, в которых доминирует традиционность отстают от развития, а также подчеркивает необходимость того, что основу идеологии модернизма составляет традиционность.

Ключевые слова: национальная культура, толерантность, мультикультурализм, межкультурный диалог, сосуществование, взаимообогащение, мультикультурное общество. 